\title{
METAPHOR- AND METONYMY-BASED COMPOUNDS IN ENGLISH: A COGNITIVE LINGUISTIC APPROACH*
}

\author{
RÉKA BENCZES
}

\begin{abstract}
The paper makes the following novel claims: (1) the semantics of noun-noun compounds which is activated by metaphor and/or metonymy (often termed as "exocentric" compounds in linguistics and generally regarded as semantically opaque) can be accounted for with the help of conceptual metaphor and metonymy theory; (2) there are regular patterns of metaphor- and metonymy-based compounds, depending on which constituent is affected by conceptual metaphor and/or metonymy. In the second part of the paper I look at a subtype of metaphor- and metonymy-based noun-noun compounds, where the simultaneous activation of both metaphor and metonymy affects the meaning, and give an account of the productive patterns that underlie this type.
\end{abstract}

\section{Introduction: the problematic nature of exocentric compounds}

Noun-noun compounds are a highly intriguing set of linguistic phenomena. Not only do they form the largest group of compounds in English (Algeo 1991), ${ }^{1}$ but children learn to produce this type of compound the earliest, from around the age of two (Clark 1981). However, what is most remarkable about these compounds is the diversity of semantic relationships that can exist between the two components on the one hand, and between the individual elements and the compound as a whole on the other. Nevertheless, however diverse the semantics of noun-noun

* I wish to thank my reviewers for the excellent remarks and observations. I am also grateful to Zoltán Kövecses, who has meticulously read through several earlier versions of this paper. Needless to say, all remaining errors are mine. The publication of the paper was supported by the Research Group for Theoretical Linguistics of the Hungarian Academy of Sciences at the University of Debrecen.

${ }^{1}$ A fifty-year-long research into the emergence of new words in the United States (Algeo, op.cit.) has managed to shed some light on contemporary word formation patterns. According to the data, compounding is the most productive word formation process: $68 \%$ of the new expressions were grouped into that category. More interestingly, $90 \%$ of the compounds were nouns. 
combinations may be, many linguists have attempted to systematise the constraints that apply in their creation and interpretation (see for example Adams 1973; Downing 1977; Jespersen 1954; Levi 1978; Marchand 1960; Ryder 1994; Warren 1978).

The most traditional and pervasive semantic classification of compounds used in linguistics is based upon the work of Bloomfield (1933), who suggested that compounds fall into two main groups. In endocentric constructions, the compound is the hyponym of the head element: apple tree is a kind of tree. In the case of exocentric or "headless" constructions, however, the compound is not a hyponym of the head element, and in the majority of cases there is some sort of metaphor or metonymy at work in the meaning of the compound. For example, blue-stocking does not denote a kind of stocking but refers to a well-educated woman. While the terms endocentric and exocentric are often used in linguistics even today (see for e.g., Adams 2001; Kiefer 1998), there are two very general-and serious - problems regarding exocentric constructions: (1) linguists do not agree as to what sort of constructions fall under the umbrella term of "exocentric compounds"; and (2) linguistic literature has a strong tendency to mention exocentric combinations only peripherally (if they are mentioned at all), and views these constructions as exceptional cases that do not follow normal and productive compound-forming patterns.

\subsection{What sort of compounds should we consider as exocentric?}

If one leafs through a number of works on English morphology, it becomes clear very quickly that there is no straightforward answer to this question. There is chaos in the literature regarding the definitional criteria for semantically exocentric compounds; descriptivists such as Bloomfield (1933), Jespersen (1954) and Marchand (1960), for example, limited their investigation to select classes of various kinds of metonymybased noun-noun combinations, and ignored metaphor-based constructions completely. In her analysis of the semantics of noun-noun combinations, Adams (1973) does make reference to "exocentric" compounds (though marginally); these are mostly constructions that are both metaphor- and metonymy-based, such as butterfingers. ${ }^{2}$ In her more recent

${ }^{2}$ Adams (op.cit.) does not specifically claim that butterfingers is a compound based on both metaphor and metonymy, yet in my view, the simultaneous activation of both cognitive devices takes place in the interpretation of the compound's 
work, Adams (2001) claims that semantically exocentric constructions are small in number and are formed on the basis of three patterns: (1) the relation between the elements is similar to that between a verb and its complement, as in pickpocket; ${ }^{3}(2)$ the elements are a combination of adjective and noun as in highbrow; and (3) the elements are a combination of noun and noun, as in spoonbill. Adams' study can be regarded as a simplification of the problem: in her understanding, the various types of exocentric compounds can be distinguished on the basis of their syntax and no further explanation is provided on the semantics of these constructions - which is in fact the most exciting question concerning exocentric compounds.

To give a generativist example as well, Levi (1978) in her far-reaching work on nominal compounds, bases her theory ${ }^{4}$ upon endocentric compounds, but takes a look at exocentric compounds as well. In her view, exocentric compounds are defined as compounds where the referent does not denote a subset of the set of objects denoted by the head noun. She lists three types of exocentric constructions: (1) compounds based on synecdoche such as blockhead that describe people and cottontail that describe animals; (2) those based on metaphor such as ladyfinger (a type of pastry) or foxglove (a type of flower); and (3) those which constitute coordinated structures (where neither noun can be taken as a head) such as secretary-treasurer or sofa-bed. Although Levi extended her interpretation of exocentric compounds to include both metonymic and

meaning: the fingers are like butter in the sense that everything slips out of one's hands (just as butter is a slippery substance), and the fingers on one's hand stand metonymically for the whole person.

${ }^{3}$ The chaos which exists among the classification of exocentric compounds is well demonstrated by the fact that Carstairs-McCarthy (1992) labels pickpocket as a prime example of a bahuvrihi type (synecdoche-based compound), which is analysed as a subcategory of exocentric compounds in Marchand (1960). Bauer (1983) also claims that bahuvrihi compounds are a type of exocentric compounds - though he extends "exocentric" to include lexicalised metaphor-based compounds as well, such as monkshood or ladysmock (for various kinds of plants).

${ }^{4}$ Levi claims that all complex nominals are derived by two syntactic processes: predicate nominalization and predicate deletion. In the latter case, the nominal compounds are a result of syntactic transformation in which phrases such as "cake with apples" surface as nominal compounds such as apple cake. The semantic relations between the member elements of the compound represent one of the nine recoverably deletable predicates. These predicates are deleted in the surface structure but the interpretation of the compound is made possible by using the reconstituted relative clause. 
metaphorical ones, we are once again left with the feeling that such a categorisation (as the previous ones mentioned above) is over-generalised. Surely metaphor and/or metonymy can act upon compounds in a number of ways, depending on which constituent of the compound is affected (or whether the meaning of the compound as a whole is activated by either of the two conceptual devices). What I wish to emphasise here is that the term "exocentric" is not a good candidate to describe compounds whose meaning is based upon metaphor and/or metonymy - for the simple reason that the term "exocentric" is used as a general, collective term to include diverse linguistic phenomena.

\section{2. "Exocentric" for exceptionality and quirkiness?}

The other major problem with the term "exocentric" is that it implies a degree of quirkiness - the word itself means that the head of the compound falls outside of the construction (hence exo). This, naturally, is not the normal state of affairs; it is a general assumption that the majority of English compounds follow the Right-Hand Head rule (Williams 1981) ${ }^{5}$ and accordingly are endocentric from both a syntactic and a semantic point of view. There are, of course, exceptions that fail to abide by these suppositions, such as exocentric or left-headed constructions. ${ }^{6}$

The fact that exocentric compounds do exist in English (even though endocentric ones are considered to be the default) might have prompted linguists to look into the nature of these constructions - yet linguistic literature has serious shortcomings on the subject. Either there is utter

\footnotetext{
${ }^{5}$ This defines the head of a morphologically complex construction as the right-hand member.

${ }^{6}$ As Bauer and Renouf (2001) point out, exocentric or left-headed compounds are regarded as exceptional cases in the sense that there are not too many of themand this is where many linguistic studies go wrong. Their corpus-based study (coming from the British newspaper Independent over a period of ten years) has shown that English neologisms thrive with cases which were taken as borderline formations, such as exocentric compounds. The case in point is that there are plenty of "unexpected trends" (op.cit., 120) in English word formation, and a proper analysis or description of the English language needs to fit these exceptional types in and provide an explanation for them. Bauer and Renouf's observation is highly relevant for the present paper as well, since they address one of the most basic questions in word formation: if a pattern is atypical, does it also mean that it is exceptional? Their paper suggests that the answer to this question is negative.
} 
neglect or exocentric compounds are considered to be special cases that cannot be fitted into a mainstream explanation of compounds. Examples are abundant. Authors such as Downing (1977) and Warren (1978), ${ }^{7}$ both of whom have written often-cited monographs on the possible semantic relationships between the constituents of noun-noun combinations, considered endocentric compounds the primary object of their respective studies. ${ }^{8}$ Linguists who have included exocentric compounds in their study very often regarded them as exceptional in the sense that they cannot be treated within the same framework as endocentric compounds. Generativists, such as Selkirk (1982), argued for the creation of separate semantic rules in the grammar by which exocentric compounds could be interpreted. ${ }^{9}$ Unfortunately no other reference is made to the nature of these rules. ${ }^{10}$

In a textbook summary of generative morphology, Katamba (1993) criticises Selkirk (1982) for introducing the idea of separate semantic rules to interpret exocentric compounds. He argues instead for a simple listing of the meanings. In Katamba's view, both idioms and exocentric compounds are listemes with regard to their semantics - which is opaque. ${ }^{11}$

${ }^{7}$ Warren (op.cit), for example, describes metaphor- and/or metonymy-based compounds as "idiosyncratic compounds" - constructions where the semantic relation between the component elements is neither explicit, nor in accordance with established patterns. She claims that such expressions are opaque as to the semantic relation between the constituents, since the hearer cannot "fall back" upon already existing patterns of English compounding.

${ }^{8}$ Ryder (1994) analysed the semantics of noun-noun compounds in elaborate detail from a cognitive linguistic viewpoint - but her study also pertains exclusively to endocentric compounds.

${ }^{9}$ Selkirk devotes only a couple of pages to the idiosyncratic nature of exocentric compounds - due most probably to the fact that the author looks upon these linguistic phenomena as exceptional when she expresses her intent to examine the "few cases of exocentric (nonheaded) compounds in English" (op.cit., 23).

${ }^{10}$ I would like to point out a positive example here as well. One of the strongest criticisms of the transformationalist/generative approach is provided by Botha (1968), who calls attention to the relative abundance of "metaphorical compounds" in the Afrikaans language. The author claims that in constructing an Afrikaans transformational generative grammar of compounds, metaphorical constructions cannot be left unconsidered. Not only does Botha call for a proper linguistic description of such compounds, but he also provides a very compact classification of such constructions.

${ }^{11}$ In his study, Kooij (1968) has also pointed out the existence of so-called idiomatic compounds (his term) whose meanings are very often based upon metaphor. However, he restricts his analysis of compounds to endocentric constructions, claiming 
This is the reason why, according to the author, exocentric compound formation is used much less frequently than endocentric compounding in the creation of new words. However, if the semantics of exocentric compounds is opaque then why bother with using them at all? It would be more sensible - following Katamba's line of reasoning - to denote things by using semantically endocentric compounds only. Yet the simple fact that English does have such constructions implies that either English speakers like to invent dim and murky terms when creating a new word for public access or that the meaning of exocentric compounds is not as opaque as it seems.

\section{The transparency of semantically "opaque" compounds}

Leaving behind the traditional notions of endo- and exocentricity, Dirven and Verspoor (1998) discuss the semantics of compounds from a more flexible perspective: the authors also argue for a cline of transparency on which compounds can be placed on the basis of the transparency of their meaning. ${ }^{12}$ At the fully productive (and transparent) end of the continuum, both parts of the compound and the semantic link between them "are unequivocally analysable and hence immediately transparent"

that - even though idiomatic compounds did originally have the same structures as regular, non-idiomatic ones - these have undergone meaning specialisation to such a degree that they cannot be described by the same set of rules, they therefore represent a different type in grammar from non-idiomatic compounds.

12 The idea of placing compounds on a cline of transparency (instead of having two clear-cut classes of endocentric and exocentric constructions) is not new - see for example Cruse (1991); Fabb (1998); Spencer (2001). In fact, Levi (1978, 63), too, proposed a "continuum of derivational transparency" for compounds. Transparency should not be confused with compositionality (see for instance Allan 1986; Cruse 1991; Fabb 1998; Katamba 1993; Langacker 1987; Matthews 1974; for an overview of the topic see Benczes 2004a), which has been often used to differentiate among phrases and compounds (black bird versus blackbird). I agree with Langacker $(1987 ; 2000)$ who claims that linguistic phenomena (including compounds) are more likely to show partial than full compositionality: blackbird (meaning a bird species) is partially compositional because, even though the composite meaning is a combination of the meanings of the components, it has undergone a specification of meaning since it refers to a specific type of black bird. In Langacker's view, when a new linguistic expression is coined, it is interpreted with a quite rich contextual and specified meaning, therefore $C \neq[A B]$. As the form gets to be established, some of this extra meaning is retained and that is the reason why most composite expressions (including compounds) have a conventionalised meaning that is more specific than their compositional value. 
(op.cit., 60), such as apple tree. In the case of partially transparent expressions, the components are still analysable but the semantic link is less apparent and insufficient to see which subcategory the meaning of the compound involves, such as blackbird, which does not denote a black type of bird but a bird species. At the other end of the continuum lie non-transparent expressions, which Dirven and Verspoor call "darkened compounds": in these cases, the authors claim, metaphorical or metonymical processes are involved in the meaning of the constructions, such as red tape, which does not describe a kind of tape but refers to a long and irritating bureaucratic procedure.

There are two main problems with Dirven and Verspoor's (1998) analysis. First, their definitions of the various degrees of transparency are very vague indeed. When is a semantic link "unequivocally analysable" in the case of transparent compounds? Are there certain semantic relations which are more transparent than others? If so, what are these? Needless to say, the problem also arises in the case of partially transparent compounds. When does a transparent compound become partially transparent? ${ }^{13}$

However, the introductory purpose of Dirven and Verspoor's (1998) textbook might offer an excuse for the relative superficiality of their definitions, as the limited space did not allow for in-depth elaborations on the various topics, including the transparency of compounds. Nevertheless, the second problem of their analysis is more serious. The authors state that non-transparent or darkened compounds are metaphorical or metonymical: yet such a claim is at odds with their explanation of information highway (metaphorically referring to the internet), which they see as "easily analysable" (op.cit., 60-1) on the basis that the metaphorical meaning of highway is linked to the source domain of traffic with the target domain information, and with the help of our cultural knowledge we know the cultural background to which the word refers. The juxtaposition is the following: if a metaphorical expression is easily analysable indeed, as the authors rightly say, then why should such a compound be placed at the non-transparent end of the continuum? The answer, in my

\footnotetext{
${ }^{13}$ In my view, partial transparency might involve some sort of meaning specialisation or generalisation, thus ashtray is not really a tray, nor a tray for ashes, but a specific kind of 'tray' for cigarette ashes. Attaché case, on the other hand, could be an example for a partially transparent compound where generalisation of meaning occurs: it is not a case used by attachés only, but by many people in all sorts of white-collar professions.
} 
view, is that there is no need for us to do so in the first place. If metaphor and metonymy are everyday processes of thought, as Lakoff and Johnson (1980) say they are, then metaphorical and metonymical compounds are just as normal and everyday constructions as nonmetaphorical or nonmetonymical ones. ${ }^{14}$

\section{What kinds of metaphor- and metonymy-based compounds are there?}

Figure 1a (after Langacker 1991, figure 7) shows the highly schematised constructional schema for forming noun-noun compounds in English, where two nouns (denoting different concepts) can be combined into one semantic unit. All the structures and categorizing relationships have the status of units, which are indicated by the boxes. Figure $1 \mathrm{~b}$ shows how we are able to arrive at the composite expression of jar lid, the composite symbolic structure of the combination of $[[\mathrm{JAR}] /[\mathrm{dga}]]$ and $[[\mathrm{LID}] /[\mathrm{IId}]]$, with the application of the noun-noun constructional schema. The assembly of this expression comes from a number of pre-existing units: the constructional schema, the components jar and lid, and the categorisation of jar and lid as nouns.

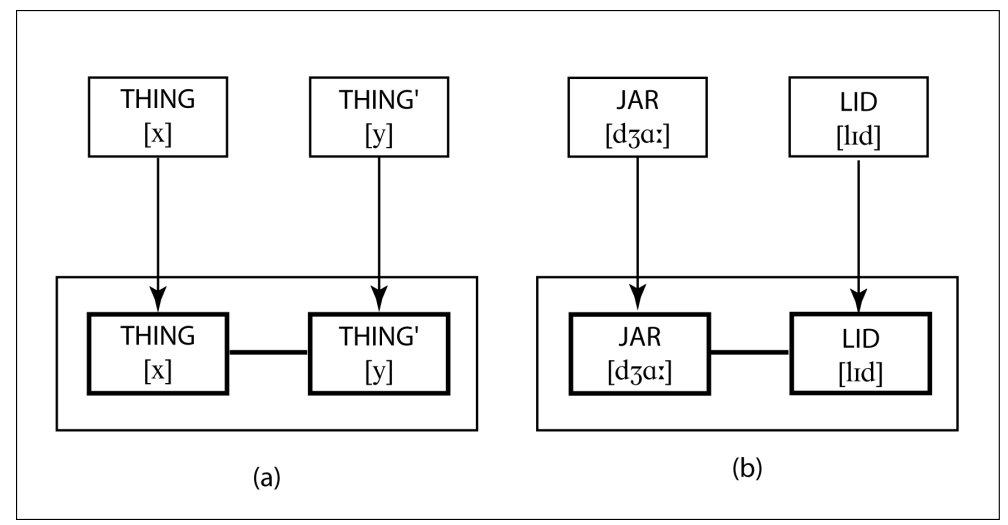

Fig. 1

The constructional schema of noun-noun compounds (a); and the constructional schema of jar lid (b) (after Langacker 1991, fig. 7)

${ }^{14}$ See also Benczes (2004a; b; forthcoming) - where I suggest using the term "creative compound" for metaphor- and/or metonymy-based compounds. 
Jar lid is an example of a regular pattern in English compounding, a sequence also observable in e.g., milk carton, salad oil, door knob, pencil eraser - to name but a few. Phonologically, both jar and lid are words, while at the semantic pole each is a noun profiling a thing. Jar profiles a specific kind of container, while lid designates the cover for a container of an unspecified nature. The composite structure jar lid consists phonologically of a two-word sequence, while semantically it profiles the cover for a jar in particular. In a construction, the component and composite structures are linked by correspondences - these specify how the components are integrated to form the composite structure (e.g., the semantic correspondences of jar lid equate the unspecified container evoked by lid to the specific container profiled by jar). In a typical construction, one component is schematic with respect to the composite structure as a whole: while both the schematic component and the composite structure construe the scene in the same fashion, particularly in regard to profiling, they differ in the level of specificity: the composite structure is more specific with regard to the thing that it profiles (jar lid is more specific than lid). In the case of $j a r$ lid, lid will function as the profile determinant, as this is the constituent that construes the same scene as the composite structure (Langacker 2000, 16-8).

Cognitive linguistics claims that the way we construe events or things can also be metaphorical or metonymical (Langacker 1987; 1991; 2000). This implies that profiling can also be affected by conceptual metaphor or metonymy. Therefore, in the case of a noun-noun constructional schema, the modifier element, the profile determinant or the semantic link between the two components can also be influenced by metaphor and metonymy. What this implies then is that there is an inventory of metaphor- and metonymy-based compounds, depending on where metaphor or metonymy acts upon the constructions: the modifier, the profile determinant, the relation between the two constituents of the compound, or the compound as a whole.

By identifying the place where conceptual metaphor or metonymy can act upon the meaning of a noun-noun compound, their systematisation $^{15}$ and the analysis of their meaning (within a cognitive linguistic framework) becomes possible. In the second part of the paper I wish to present one subtype of metaphor- and metonymy-based compounds:

${ }^{15}$ For a full, systematic description of the possible patterns underlying English
metaphor- and/or metonymy-based noun-noun compounds, see Benczes (2004a). 
those whose meaning is influenced by the simultaneous activation of both metaphor and metonymy. I claim that there are regular patterns by which such compounds are formed in English; I have identified four such patterns. After providing a critical overview of previous analyses of metaphor- and metonymy-based compounds, I will give an account of the patterns I have uncovered-I will give examples for all four and will also provide full analyses of the meanings with the help of conceptual metaphor and metonymy theory. ${ }^{16}$

\section{The analysis of metaphor- and metonymy-based compounds in linguistic literature}

Needless to say, the idea that metaphor and metonymy can simultaneously act upon the meaning of a noun-noun combination is not new; Warren (1992), for instance, discusses (a couple of) compounds where "metaphors within metonymies" and "metonymies within metaphors" are at work. In her view, hammerhead ('a stubborn person') is an example of the former, where the hammer metaphorically refers to something hard, and the compound as a whole is a PART FOR WHOLE metonymy ${ }^{17}$ (the head is used to refer to the whole person).

Warren (1992) also claims that the compound jellybean ('a stupid person') is a further example of a metaphor in a metonymy. She argues that the motivation for this construction is based on the metonymy that somebody has something that is like a jellybean in that it "contains fluff and is egg-shaped" (op.cit., 95). There are numerous idiomatic expressions in English which have a similar meaning as jellybean, for example be bone-headed from the neck up or be soft-headed, which are in some way related to the head (Benczes 2002). It is probable that jellybean also

\footnotetext{
${ }^{16}$ Note that conceptual metaphor and metonymy are not adequate to account for all the various types of metaphor- and/or metonymy-based compounds - I have made extensive use of blending theory for example in the analysis of other types, which I am unable to present here due to lack of space, but see Benczes (2004a;b; forthcoming) for plenty of examples. On the application of blending theory in the analysis of English compounds, see Coulson (2000); Fauconnier-Turner (2002); Sweetser (1999); for an overview see Benczes (2004a). For a concise overview on the cognitive linguistic theory of conceptual metaphor and metonymy see Kövecses (2002).

${ }^{17}$ As is customary in cognitive linguistics, conceptual metaphors and metonymies will be written in SMALL CAPITALS.
} 
refers to the head of a stupid person, as a jellybean does not contain anything solid inside (the similarity is based on the conception that a stupid person does not have too many ideas in the head), and a head that is like a jellybean might imply that somebody lacks the usual intellectual capacities. Clockwork orange ('a person made into an automaton') is a metonymy within a metaphor: the hero of the novel Clockwork Orange is in a metonymical relationship with the text itself (PLACE FOR PERSON), and there is also a metaphor at work, by which a person is likened to a machine.

Reference should also be made to Goossens (1995), who created the term "metaphtonymy" to refer to the process when both metaphor and metonymy act upon an idiomatic expression. For example, to beat one's breasts ('to make an open noisy show of sorrow that may be partly pretence') represents a case of metaphor from metonymy: the metonymic basis is the religious practice of beating one's breast while one confesses one's sins publicly. This image is then mapped through metaphor onto nonreligious situations as well. Goossens also identified a metonymy-withinmetaphor pattern, where there is a "built-in metonymy" (op.cit., 169) in the metaphor: in shoot one's mouth off ("talk foolishly about what one does not know about or should not talk about') the source domain of firearms is mapped onto the target domain of unthoughtful linguistic action. Mouth, at the same time, metonymically stands for a person's speech faculty.

Geeraerts (2002) analysed the interaction of metaphor and metonymy in composite expressions, such as idioms and compounds. He claims that there are plenty of compounds that are neither purely metaphorical, nor purely metonymical, but involve both types of meaning extension. According to Geeraerts, such cases can be classified into three main categories: metaphor and metonymy can occur in a compound expression (1) consecutively; (2) in parallel; and (3) interchangeably.

An example of the first category is schapenkop ("sheep's head", i.e., 'dumb person'), where the analysis of the compound's meaning involves two steps: first, "sheep's head" is metaphorically extended towards the reading 'a human head like that of a sheep, a stupid head', and second, a metonymical step leads to 'a person with a head like that of a sheep, a stupid person'. The compound droogkloot ("dry testicle" - 'boring person, bore') exemplifies the second case, when metaphor and metonymy act upon the meaning in parallel. The compositional, literal reading "dry testicle" metonymically stands for "a person with dry testicles". This 
reading, however, serves as the input for a further metaphorical extension, leading to the boring person sense. Badmuts ("swimming cap" 'bald person') represents the third category, i.e., the interchangeability of metaphor and metonymy. According to Geeraerts, the compound can be analysed in two ways: either "swimming cap" leads metonymically to "a person who looks as if he was wearing a swimming cap, a bald person', or "swimming cap" is metaphorised as "a head that looks as if it is covered by a swimming cap, a bald head', and from there metonymically extended to 'a bald-headed person'. As the author points out, the semantic explanation can go either way, there is no principle by which one line of analysis can be favoured over the other.

I could not agree more. In my view, it is very difficult-if not impossible - to decide even in cases such as schapenkop which process acts upon the compound first, metaphor or metonymy. For this reason, I believe that forming categories on the basis of the metaphorical and metonymical sequence is pointless. Moreover, as badmuts also shows, whichever line of analysis we choose, the result is the same; and that is what counts. For these reasons I recommend an approach which concentrates on the various ways metaphor and metonymy can act upon the various parts of the compound expression, and not on the possible sequence of the cognitive processes involved.

\section{Typology and analysis of metaphor- and metonymy-based compounds}

In this section, I wish to go beyond the analyses proposed by Warren (1992), Goossens (1995) and Geeraerts (2002), and show that conceptual metaphor and conceptual metonymy can act upon the meaning of nounnoun compounds in a remarkable variety of ways. I claim that there are distinct patterns of compounds that are based upon conceptual metaphor and metonymy; these patterns seem to be productive. I have identified four such patterns, whereby conceptual metaphor and metonymy act simultaneously upon the compound in the following ways: (1) metaphorbased semantic relationship between the constituents of the compound and metonymy-based modifier; (2) metaphor-based semantic relationship between the constituents of the compound and metonymy-based profile determinant; (3) metonymy-based modifier and metaphor-based profile determinant; and (4) metaphor-based modifier and metonymy-based pro- 
file determinant. These four main categories yield various subtypes, based on the type of conceptual metaphor and metonymy participating in the meaning of the compound.

\subsection{Metaphor-based semantic relationship between the constituents of the compound and metonymy-based modifier}

In this subsection, I will discuss those compounds that, apart from a metaphorical relationship between $\mathrm{N}_{1}$ and $\mathrm{N}_{2}$, also involve metonymy, such as macarena page ('a webpage capitalising on a current fad, they are usually full of fluff and have a short life expectancy'; source: www.wordspy.com). The meaning of the compound is based upon the activation of both metaphor and metonymy, since there is a metaphor that provides the understanding of $\mathrm{N}_{2}$ in the terms of $\mathrm{N}_{1}$ on the one hand (a webpage that is like the macarena dance in the sense that the macarena was a dance that was immensely popular a couple of years ago, though this popularity lasted for only a couple of weeks), and a metonymy that is activated by the concept denoted by $\mathrm{N}_{1}$ on the other hand (macarena page does not contain information about the macarena - it is a webpage that holds information about a current fad, therefore macarena stands for any fad that has a short life expectancy but enjoys huge popularity).

Figure 2 shows the structure of these constructions. There are two concepts, $\mathrm{X}$ and $\mathrm{Y}$, which have corresponding phonological poles, $[\mathrm{x}]$ and [y] respectively. There is a perceived similarity between the two concepts denoted by the two constituents of the compound which provides the basis of the meaning of the whole. Moreover, there is a metonymy acting upon the meaning of the compound as well. The first constituent can be regarded as a unit whose semantic pole is embedded in an Idealised Cognitive Model (ICM for short). ${ }^{18}$ Since $\mathrm{X}$ is a part of the ICM, it is related to it through a conceptual metonymy.

${ }^{18}$ The notion of idealised cognitive models, or ICMs, was introduced by Lakoff (1987). A very good explanation of what ICMs are is offered by Radden and Kövecses $(1999,20)$ : "the ICM concept is meant to include not only people's encyclopaedic knowledge of a particular domain but also the cultural models they are part of. The ICM notion is not restricted to either the world of reality, the world of conceptualisation or the world of language but [...] may cut across these ontological realms." This understanding of ICMs will be used in this paper as well. 


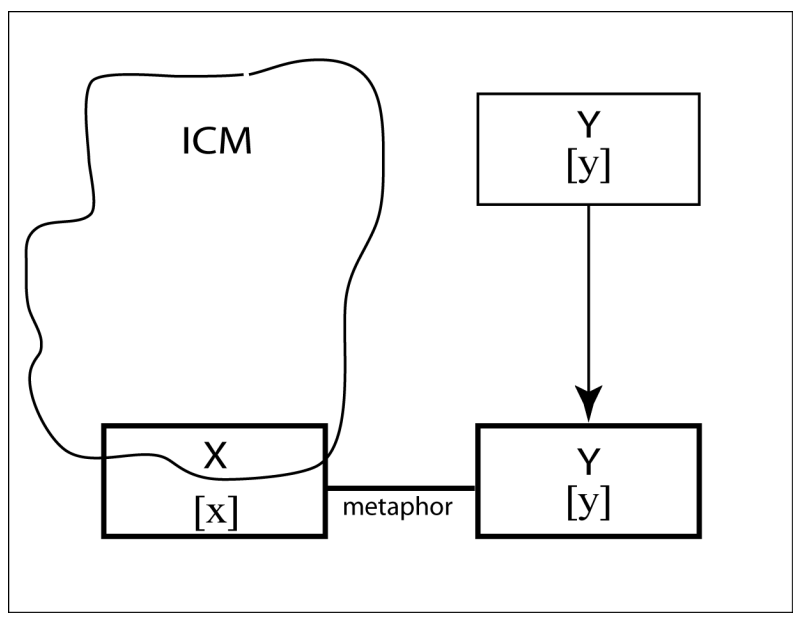

Fig. 2

Model of a creative compound with a metaphor-based relationship between the two constituents and a metonymy-based modifier

\subsubsection{Sign metonymies}

According to Radden and Kövecses $(1999,24)$, the pairing of a concept with a form gives rise to the Sign ICM. The authors provide the example of the word form dollar or the dollar sign $\$$, which are linked with the 'currency denomination for dollar'. This relationship is based upon the rule that the form metonymically stands for the concept it denotes, which is expressed in the following metonymy: FORM FOR CONCEPT. As Radden and Kövecses argue, the very nature of language is based upon this metonymic principle, which is described by Lakoff and Turner (1989, 108) as WORDS STAND FOR THE CONCEPT THEY EXPRESS: "[s]ince we have no other means of expressing and communicating our concepts than by using forms, language as well as other communication systems are of necessity metonymic. It is also for this reason that we fail to notice the metonymic character of language" (ibid.).

Alpha geek ("the person with the most technological prowess in an office or a department') and alpha girl ('the dominant member in a group of girls' $)^{19}$ exemplify typical cases of the Sign metonymy. First of all, we have a human being, a girl and a geek, who are likened to the first letter of the Greek alphabet. The meaning of the whole denotes girls and geeks

${ }^{19}$ Both alpha geek and alpha girl come from an internet-based collection of English neologisms; http://www.wordspy.com. 
who are the first in their group; this "prime position" is represented by the concept of the letter alpha. How is the concept of primariness linked to the letter $\alpha$ ?

It is this metonymy, FORM FOR CONCEPT, which is at work in the first constituent of alpha geek and alpha girl: the form $\alpha$ stands for the concept it expresses - namely it being the first letter in the Greek alphabet. This concept of primariness is the shared similarity that exists between alpha and geek on the one hand, and alpha and girl on the other hand. However, there is a slight difference in meaning between the two alphas: in the former compound, it denotes the highest level of technological knowledge, while in the latter expression it is used to denote the quality of having the greatest influence and popularity within a group. How can alpha be used in these compounds while meaning different - though - related things?

According to Langacker (1991), semantic relationships are based on the identification of an appropriate active zone of the elaborated concept. This means that it is less probable for alpha geek to mean, for example, 'the most popular IT person in an office' because the meaning of geek brings into focus the frame of a person who is an expert with computers. ${ }^{20}$ Thus the active zone of geek is technological prowess (and not popularity) - this quality is emphasised by alpha. In the case of alpha girl, however, the profile determinant has a more general meaning, and denotes a young female. Since the frame of girl is so general, alpha (denoting 'primariness') cannot bring into focus any sort of quality as in alpha geek for instance. The meaning negotiation between the two constituents of the compound results in the meaning of 'a girl who is the first among other girls'.

\subsubsection{Concept metonymies}

As Radden and Kövecses (1999) argue, concept metonymies involve a shift from Concept ${ }_{\mathrm{A}}$ to Concept $_{\mathrm{B}}$, where the two concepts are part of the same ICM and are related to each other in some specific way. The two major types of metonymy-producing relationships can be subsumed under two general conceptual configurations: (1) whole ICM and its parts (e.g., PART OF A THING FOR A WhOle Thing, as in England for 'Great

\footnotetext{
${ }^{20}$ According to the CCED, geek means "[somebody] who is skilled with computers and who seems more interested in them than in people".
} 
Britain'); and (2) parts of an ICM (e.g., PlaCe For PROduCt MAdE THERE, as in champagne).

\subsubsection{MEMBER OF A CATEGORY FOR THE CATEGORY}

There are numerous compound expressions where one entity (denoted by $\left.\mathrm{N}_{2}\right)$ is compared to another entity $\left(\mathrm{N}_{1}\right)$ that is an instantiation of the MEMBER OF A CATEGORY FOR THE CATEGORY metonymy. As stated by Radden and Kövecses $(1999,34)$, a category and its members form an ICM, the Category-and-Member ICM, which can be analysed as an instance of the whole-part configuration, more precisely as an instance of the PART FOR WHOLE metonymy.

Waitress mom ('a woman who is married, has children, works in a low-income job, and has little formal education') ${ }^{21}$ is a compound that can be regarded as a type of metonymical construction of the MEMBER OF A CATEGORY FOR THE CATEGORY conceptual metonymy. The mother, denoted by the second constituent, is likened to a waitress, as denoted by the first constituent of the compound. However, the concept of waitress metonymically stands for the whole social class of married women working in low-income jobs.

Why is waitress selected to stand in the place of the modifying element, as opposed to e.g., hairdresser, secretary or saleswoman? The answer I believe lies in what Lakoff (1987, 79; after Rosch 1978) calls "prototype effect": a subcategory or a member of a subcategory is selected to comprehend the category as a whole because it possesses all the prototypical attributes of the category. This does not mean that all waitresses are married, have children and are badly paid, but rather that our culture takes the waitress as a social stereotype of her category (mothers who work in a badly paid job and have little formal education). According to Lakoff (ibid.), "[s]ocial stereotypes are cases of metonymywhere a subcategory has a socially recognized status as standing for the category as a whole, usually for the purpose of making quick judgments about other people."

However, the meaning of waitress mom would never have arisen without a further social stereotype: that of the housewife mother (Lakoff 1987, 77-84). Lakoff claims that the category of mother has a central, prototypical case, with a mother who is married to the father of her natural child and stays at home all day with her children. Thus the ex-

\footnotetext{
${ }^{21}$ Source: www.wordspy.com.
} 
pression of working mother does not simply mean a mother who happens to be working, but the category of working mother is defined in contrast to the stereotypical housewife mother. As Lakoff argues, the stereotypical view is that mothers who do not stay at home all day with their children cannot properly care for them and bring them up. There is also the stereotypical image of work, which is something that is done away from home, and housework and child-rearing do not count. This stereotype is fought against with the bumper sticker "Every mother is a working mother" (op.cit., 80). Thus, similarly to working mother, waitress mom is also defined on the background of the housewife mother stereotype, as a less prototypical member of the mother category, as she does not stay at home with her children but goes out to work instead. However, similarly to housewife mother, waitress mom also functions as a stereotype, namely that of the category of low-paid, under-educated working mothers.

\subsubsection{PRODUCER FOR PRODUCT}

This metonymy is an instantiation of the Production ICM (RaddenKövecses 1999, 39-40), which involves actions in which one of the participants is a product created by the action. The PRODUCER FOR PRODUCT, or more specifically the ARTIST FOR HIS WORK, is at play in picasso porn ('the scrambled signal of a pornographic cable channel as seen by a nonsubscriber'). ${ }^{22}$ What we have is porn (denoted by $\mathrm{N}_{2}$ ) that is like the work of Picasso (denoted by $\mathrm{N}_{1}$ ): the nonsubscriber sees only very scrambled images of naked women that resemble the work of the cubist artist. As Radden and Kövecses argue (ibid.), it is the very close association that exists between an artist and his work in our culture that provides the immediate understanding of the metonymical character of $\mathrm{N}_{1}$. The shape of paintings - usually rectangular - is similar to the shape of a television set; the frame of the painting maps onto the television box, while the painting that is contained on the canvas (in between the frames) corresponds to the television screen. These mappings imply that there is a one-shot image metaphor involved between the source domain of a painting and the target domain of a television set.

A very relevant question to ask about picasso porn is why it is Picasso who is selected to metonymically stand for his work, why not some other cubist or expressionist painter, such as Braque, Matisse or Kandinksy? I believe that there are two main reasons for choosing Picasso. First, he

\footnotetext{
${ }^{22}$ Source: www.wordspy.com.
} 
was the artist who established abstract painting in the form of cubism, and became famous for depicting quite a few women on his canvas within this new style of painting which greatly distorted the original shapes and figures. The name of Picasso is thus intricately linked with paintings of distorted women (and it should not be overlooked that it is his Les Demoiselles d'Avignon, which can be considered to be one of his most well-known paintings), more than e.g., Kandinsky or Matisse. Second, Picasso alliterates with porn - which is further evidence for the significant role that phonological considerations play in the formation of metaphorand metonymy-based compounds.

\subsection{Metaphor-based semantic relationship between the constituents of the compound and metonymy-based profile determinant}

This section focuses on metaphor- and metonymy-based compounds where there is a metaphorical relationship between the modifier and the profile determinant; at the same time there is also a conceptual metonymy acting upon the head element (Figure 3). I believe that it is this type of creative compounding pattern that underlies hammerhead ('a stubborn person'). ${ }^{23}$ What happens here is that the profile determinant, head, stands in a metaphorical relationship to the modifier, hammer. Thus we have a head that is like a hammer: hard, clumsy and unyielding. At the same time, head metonymically stands for the person via a PART FOR WHOLE conceptualisation, more specifically HEAD FOR THE PERSON. This latter metonymy underlies several compounds and idiomatic expressions in English, such as hothead ('a person who is easily aroused to anger'), heads will roll ('those responsible for the blunder will be dismissed'), to fling oneself at someone's head ('to pursue someone in the spirit of infatuation'). ${ }^{24}$ It is important to note that the sequence of the metaphor and the metonymy acting upon the compound in this case is definitely relevant to the meaning of the expression: hammerhead cannot be analysed by taking the metonymy first, as that would yield hammer person - a compound that could mean e.g., a person who prefers to work

${ }^{23}$ Hammerhead emerges in both Ryder's (1994) and Warren's (1992) writings, although they use it to refer to two different entities. In Ryder's case, it means 'a type of shark', while in Warren's usage it denotes 'a stubborn person'. In the paper I will use Warren's definition of the compound.

${ }^{24}$ All the examples are from PDEI. 
with a hammer as opposed to working with a drill (as in the following comment: "Oh, I'm a hammer person when it comes to DIY").

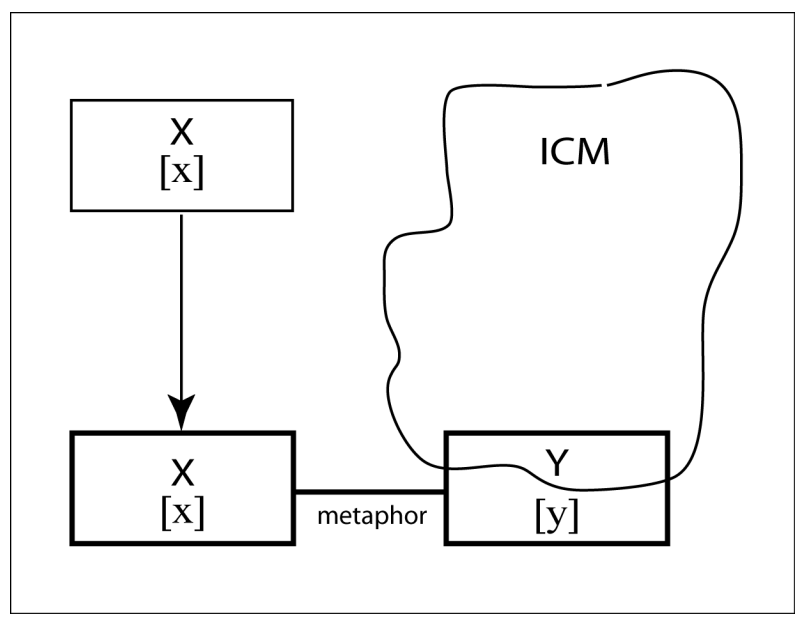

Fig. 3

Model of a creative compound with a metaphor-based relationship between the two constituents and a metonymy-based profile determinant

A further compound I wish to analyse in this section, bell-bottoms ("trousers that are very wide at the bottom of the leg'), is based upon an image metaphor (Figure 4).

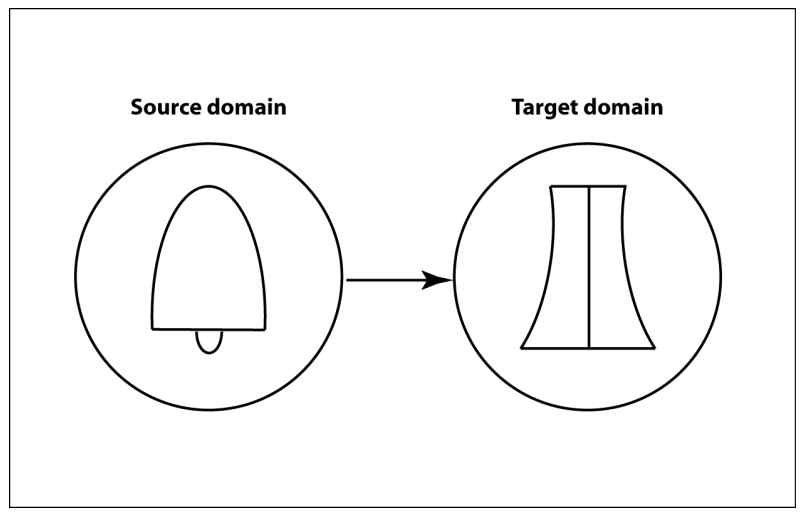

Fig. 4

Representation of the image schema of bell-bottoms

Image metaphors map relatively little from source to target. In the case of bell-bottoms, the skeletal shape of a bell is mapped onto the shape of 
the bottom part of a pair of trousers. The profile determinant of the compound, bottoms, serves as a metonymical cue by which the complete garment, i.e., the pair of trousers can be accessed through the PART FOR WHOLE conceptual metonymy. I would like to emphasise that my analysis does not wish to take a stand on the sequence of metaphorical and metonymical processing: for instance, bell-bottoms can just as well be accounted for by claiming that metonymy acts upon the whole compound, i.e., 'the bell-shaped bottoms' metonymically stand for 'a pair of trousers which has bell-shaped bottoms'. Whichever line of approach is chosen, conceptual metaphor and metonymy take centre stage in the semantics of the construction.

\subsection{Metonymy-based modifier and metaphor-based profile determinant}

In this section, I will discuss compound expressions that have a metaphorical profile determinant and whose modifying element is based upon some sort of conceptual metonymy. In the case of alpha geek and alpha girl it has already been shown that the meaning of the first constituent is understood via the FORM FOR CONCEPT metonymy, where the form (in this case the letter " $\alpha$ ") stands for the concept it denotes - that is, it being the first letter of the Greek alphabet. It is this concept of "primariness" that is understood by the word alpha in these constructions. Alpha pup ('market research jargon for the kid who is deemed by his or her peers to be the "coolest" in their school, neighbourhood or town') ${ }^{25}$ is more similar in meaning to alpha girl than alpha geek, where the expression denotes 'a girl who is the first among other girls'. In both alpha girl and alpha pup, the profile determinant has a general meaning, and thus alpha (denoting 'primariness') cannot bring into focus any sort of quality as in alpha geek for instance. The meaning negotiation between the two constituents of alpha and pup results in the meaning of a kid who is the "coolest" of all, i.e., the child with the largest influence in his/her group.

The metaphorical profile determinants of the alpha pup can be accounted for by the everyday conceptualisation of humans as animals, based upon The Great Chain of Being metaphor system (Lakoff-Johnson 1980). In the case of alpha pup, humans are understood as dogs, with the "help" of the PEOPLE ARE DOGS conceptual metaphor (which

\footnotetext{
${ }^{25}$ Source: www.wordspy.com.
} 
is a submetaphor of the more general PEOPLE ARE ANIMALS conceptual metaphor). ${ }^{26}$

In the case of gutter bunny ('mountain biker slang for a person who commutes to work on a bicycle'), ${ }^{27}$ the modifier is rooted in our cultural knowledge of cycling in the city. In urban neighbourhoods, the edges of the roads are created so as to form gutters where the water can collect and flow away. If there is no cycle path, then cyclists use the side of the road for riding (where the gutter is located). All this information is packed into gutter, through which we can access the Cycling in the City ICM. ${ }^{28}$ The metaphorical profile determinant, bunny, activates mappings between a person who cycles to work and a rabbit. In my opinion, the quality of swiftness that we associate with rabbits (as opposed to the slowness of a tortoise) is mapped onto the cyclist: once again it is a part of our cultural knowledge (and part of the Cycling in the City ICM) that getting about with a bicycle in a city is very often a much faster means of travel than doing so with a car or public transportation. As a last note I wish to add that the constituents of gutter bunny exhibit a LOCATION schema (i.e., a location-located semantic structure), similarly to plenty of other compounds of English (such as belly button for instance).

\subsection{Metaphor-based modifier and metonymy-based profile determinant}

Acidhead ('an LSD user') ${ }^{29}$ represents a compound where the modifier is metaphor-based, while the profile determinant is metonymy-based. The compound can be paraphrased as 'a head that is full of acid', where the LSD IS ACID conceptual metaphor provides the understanding of acid as the drug in question. The compound evokes an image of a head full of acid - this CONTAINMENT schema can be accounted for by THE HEAD IS A CONTAINER conceptual metaphor, which is very prevalent in English and underlies numerous idiomatic expressions. For instance, Benczes (2002)

\footnotetext{
${ }^{26}$ It needs to be emphasised that puppy does turn up in a number of English idioms, denoting a young person: a puppy/young puppy — 'an arrogant or conceited young man', puppy fat - 'plumpness that the boy or girl will shed when reaching maturity', puppy love - 'the love of a very young, immature person' (all the examples are from PDEI).

${ }^{27}$ Source: www.wordspy.com.

${ }^{28}$ This ICM is of course different to the Cycling in the Countryside ICM, where there are no gutters for instance.

${ }^{29}$ Source: LDOCE.
} 
analyses idioms that contain the word head in them and shows that basic metaphors such as THE HEAD IS A CONTAINER and IDEAS ARE PHYSICAL OBJECTS motivate idioms such as need to have one's head examined and have rocks in one's head. In fact, the image of a head full of acid also suggests that there is no place left in the container/head for other "objects", such as ideas. Therefore, somebody who uses LSD on a regular basis runs the danger of losing the ability to think rational thoughts.

Needless to say, the metonymical profile determinant provides access to LSD addicts through the HEAD FOR THE PERSON conceptual metonymy. The question can of course be raised why head is used as the reference point in order to access the whole person, instead of some other body part. I believe that two arguments can be put forward in favour of head. First, the HEAD FOR THE PERSON conceptual metonymy is highly conventional and crops up often in English, both in compounds and in idiomatic expressions (see section 5.2). Second, the effects of LSD - which is a hallucinogenic drug - are felt primarily in the head.

It is quite interesting about the semantics of this compound that, although the meaning of the overall expression is somebody who is addicted to LSD and uses it regularly, neither acid nor head implies this habituality. This, I believe, can be accounted for by a further conceptual metonymy acting upon the compound as a whole. Being on LSD can be construed with the help of the Event ICM (Radden-Kövecses 1999, 32), which can be metaphorically viewed as containing subparts, or rather subevents. In the case of acidhead, the habitual state of being under the influence of LSD stands for the present state (even if the person denoted by the compound is not taking drugs at a given moment). Therefore, a PART FOR WHOLE metonymy - HABITUAL FOR PRESENT - accounts for the aspect of regularity that is implied by the compound.

\section{Conclusion}

Traditionally, noun-noun combinations were classified into two semantic groups: endocentric and exocentric compounds. In the case of endocentric compounds, the concept designated by the compound represents a subcategory of the entity expressed by the head noun (thus apple tree is an endocentric compound because it is a type of tree). Most compounds of English are endocentric. Since the class of exocentric or headless compounds is much smaller, they have been generally regarded as exceptional cases, which fail to abide by normal compound formation rules, and for 
this reason they have been excluded from a systematic linguistic analysis. Cognitive linguistics adopts a different approach, claiming that the analysability of nominal constructions is not a yes-no question but an issue of degree: thus there are transparent expressions such as apple tree on the one end of the spectrum, and semantically opaque cases like red tape on the other end.

The paper has argued that metaphor- (and/or metonymy-) based compounds such as red tape are not semantically opaque, but can be systematically analysed with the help of cognitive linguistic tools such as conceptual metaphor and metonymy. To prove this point, the paper focused on noun-noun compounds where the meaning is affected by conceptual metaphor and metonymy. Although both Warren (1992) and Goossens (1995) have noticed that the meaning of compounds can be based upon metaphor and metonymy, their analyses were restricted to a couple of examples. Geeraerts (2002) attempted to systematise metaphorical and metonymical compounds (it should be emphasised that his analyses were based upon Dutch - not English - examples), but he concentrated on the sequence by which metaphor and metonymy is activated in the meaning of the compound expression. The problem with this line of analysis is that it is often very difficult to decide which process acts upon the meaning of the compound first - metaphor or metonymy?

The present paper attempted to go beyond previous analyses by systematically mapping the various patterns by which metaphor- and metonymy-based compounds are formed in English. I have claimed that there are distinct patterns of compounds that are based upon conceptual metaphor and metonymy; these patterns seem to be productive. I have identified four such patterns, whereby conceptual metaphor and metonymy act simultaneously upon the compound in the following ways: (1) metaphor-based semantic relationship between the constituents of the compound and metonymy-based modifier; (2) metaphor-based semantic relationship between the constituents of the compound and metonymybased profile determinant; (3) metonymy-based modifier and metaphorbased profile determinant; and (4) metaphor-based modifier and metonymy-based profile determinant.

I wish to emphasise that my analyses do not wish to take a stand on the sequence of metaphor and metonymy acting upon the meaning of the noun-noun combination: as I have pointed out with respect to acidhead, for instance, there are several ways of proceeding with the analysis. Nevertheless, whichever line of enquiry is chosen, the result is the same: with 
the help of cognitive linguistic tools, the meaning of such compounds can be explained. This implies that a cognitive linguistic theory can in fact account for a class of compounds that have been mostly regarded as peripheral members of the English language.

\section{References}

Adams, Valerie 1973. An introduction to Modern English word formation. Longman, London.

Adams, Valerie 2001. Complex words in English. Longman, Harlow.

Algeo, John (ed.) 1991. Fifty years among the new words: A dictionary of neologisms, 1941-1991. Cambridge University Press, Cambridge.

Allan, Keith 1986. Linguistic meaning, vols. I and II. Routledge \& Kegan Paul, London \& New York.

Bauer, Laurie 1983. English word-formation. Cambridge University Press, Cambridge.

Bauer, Laurie - Antoinette Renouf 2001. A corpus-based study of compounding in English. In: Journal of English Linguistics 29 : 101-23.

Benczes, Réka 2002. The semantics of idioms: a cognitive linguistic approach. In: The Even Yearbook 5:17-30. (www.btk.elte.hu/delg/publications)

Benczes, Réka 2004a. Creative compounding in English. Doctoral dissertation, Eötvös Loránd University, Budapest.

Benczes, Réka 2004b. On the analysability of English exocentric compounds. In: Jezikoslovlje $5: 5-25$.

Benczes, Réka forthcoming. Creative noun-noun compounds. In: Annual Review of Cognitive Linguistics.

Bloomfield, Leonard 1933. Language. The University of Chicago Press, Chicago.

Botha, Rudolf P. 1968. The function of the lexicon in transformational generative grammar. Mouton, The Hague.

Carstairs-McCarthy, Andrew 1992. Current morphology. Routledge, London \& New York.

Clark, Eve V. 1981. Lexical innovations: How young children learn to create new words. In: Werner Deutsch (ed.): The child's construction of language, 299-328. Academic Press, London.

Coulson, Seana 2000. Semantic leaps: Frame-shifting and conceptual blending in meaning construction. Cambridge University Press, Cambridge.

Cruse, David A. 1991. Lexical semantics. Cambridge University Press, Cambridge.

Dirven, René-Marjorie Verspoor 1998. Cognitive exploration of language and linguistics. John Benjamins, Amsterdam.

Downing, Pamela 1977. On the creation and use of English compound nouns. In: Language $53: 810-42$.

Fabb, Nigel 1998. Compounding. In: Andrew Spencer-Arnold M. Zwicky (eds): The handbook of morphology, 66-84. Blackwell, Oxford \& Malden MA.

Acta Linguistica Hungarica 52, 2005 
Fauconnier, Gilles - Mark Turner 2002. The way we think: Conceptual blending and the mind's hidden complexities. Basic Books, New York.

Geeraerts, Dirk 2002. The interaction of metaphor and metonymy in composite expressions. In: René Dirven - Ralf Pörings (eds): Metaphor and metonymy in comparison and contrast, 435-65. Mouton de Gruyter, Berlin.

Goossens, Louis 1995. Metaphtonymy. The interaction of metaphor and metonymy in figurative expressions for linguistic action. In: Louis Goossens - Paul Rauwels Brygida Rudzka-Ostyn - Anne-Marie Simon-Vandenbergen - Johan Vanparys (eds): By word of mouth: Metaphor, metonymy and linguistic action in a cognitive linguistic perspective, 159-74. John Benjamins, Amsterdam \& Philadelphia.

Jespersen, Otto 1954. A Modern English grammar on historical principles, Part VI: Morphology. Bradford \& Dickens, London.

Katamba, Francis 1993. Morphology. Macmillan, Houndmills \& London.

Kiefer, Ferenc 1998. Alaktan. In: Katalin É. Kiss-Ferenc Kiefer-Péter Siptár: Új magyar nyelvtan [A new Hungarian grammar], 187-290. Osiris Kiadó, Budapest.

Kooij, Jan G. 1968. Compounds and idioms. In: Lingua 21 : 250-68.

Kövecses, Zoltán 2002. Metaphor. A practical introduction. Oxford University Press, Oxford.

Lakoff, George 1987. Women, fire, and dangerous things. The University of Chicago Press, Chicago.

Lakoff, George-Mark Johnson 1980. Metaphors we live by. The University of Chicago Press, Chicago.

Lakoff, George - Mark Turner 1989. More than cool reason: A field guide to poetic metaphor. The University of Chicago Press, Chicago.

Langacker, Ronald 1987. Foundations of cognitive grammar. Theoretical prerequisites. Vol. 1. Stanford University Press, Stanford.

Langacker, Ronald W. 1991. Concept, image, and symbol. The cognitive basis of grammar. Mouton de Gruyter, Berlin.

Langacker, Ronald W. 2000. Grammar and conceptualization. Mouton de Gruyter, Berlin.

Levi, Judith N. 1978. The syntax and semantics of complex nominals. Academic Press, New York.

Marchand, Hans 1960. The categories and types of present-day English wordformation: A synchronic-diachronic approach. Otto Harrassowitz, Wiesbaden.

Matthews, Peter H. 1974. Morphology. Cambridge University Press, Cambridge.

Radden, Günter - Zoltán Kövecses 1999. Towards a theory of metonymy. In: KlausUwe Panther-Günter Radden (eds): Metonymy in language and thought, 17-59. John Benjamins, Amsterdam.

Rosch, Eleanor 1978. Principles of categorization. In: Eleanor Rosch-B. B. Lloyd (eds): Cognition and categorization, 27-48. Lawrence Erlbaum, Hillsdale NJ.

Ryder, Mary A. 1994. Ordered chaos. The interpretation of English noun-noun compounds (Studies in Linguistics 123). University of California Press, Berkeley \& Los Angeles. 
Selkirk, Elizabeth O. 1982. The syntax of words (Linguistic Inquiry Monograph 7). MIT Press, Cambridge MA.

Spencer, Andrew 2001. Morphology. In: Mark Aronoff-Janie Rees-Miller (eds): The handbook of linguistics, 213-38. Blackwell, Oxford \& Malden MA.

Sweetser, Eve 1999. Compositionality and blending: semantic composition in a cognitively realistic framework. In: Theodore Janssen-Gisela Redeker (eds): Cognitive linguistics: Foundations, scope, and methodology, 129-162. Mouton de Gruyter, Berlin.

Warren, Beatrice 1978. Semantic patterns of noun-noun compounds (Gothenburg Studies in English 41). Gothenburg University Press, Gothenburg.

Warren, Beatrice 1992. Sense developments. Almqvist \& Wiksell, Stockholm.

Williams, Edwin 1981. On the notions "lexically related" and "head of a word". In: Linguistic Inquiry $12: 245-274$.

Dictionaries consulted

CCED $=$ Collins Cobuild English Dictionary for Advanced Learners. 2001. 3rd edition. HarperCollins Publishers, Glasgow.

LDOCE = Longman Dictionary of Contemporary English. International Students Edition. 1999. 3rd edition, 6th impression. Longman, Harlow.

PDEI = Gulland, Daphne M. - David G. Hinds-Howell (eds) 1994. The Penguin Dictionary of English Idioms. Penguin Books, London.

Internet sources

http://www.wordspy.com.

Address of the author: Réka Benczes

Department of American Studies

Eötvös Loránd University

Ajtósi Dürer sor 19-21.

H-1146 Budapest

Hungary

rbenczes@yahoo.com 